\title{
The Relationship of Radiological Value and Functional Scale of Lower Motion Devices in Patients with Bone Defects Given Synthetic Bone Graft and BMP2
}

\author{
Farid Ibrahim, Ismail Mariyanto, Hari Wujoso
}

Masters Program in Family Medicine, Universitas Sebelas Maret

\begin{abstract}
Background: Broken bones in a severe lower motion device, especially those associated with a bone defect, often fail or are slow to fuse. The possibility of non-union in patients triggering clinicians to use bone-grafting as part of a procedure aims at achieving the union. The Gold Standard is to use autogenous bone graft, but it actually has some disadvantages. To overcome this, there are alternative measures of bone grafting. Hydroxyapatite is known to be synthetic bonegraft which has good osteoconductive properties. For hydroxyapatite, it has been widely used and easily available. Bone morphogenetic proteins (BMPs) are the family of osteo-inductive proteins in the bone matrix. This study aims to evaluate the effectiveness of synthetic bone graft and BMP-2 as a bonegraft in the process of bone healing with "bone defect" in long bones by evaluating the process of radiological closure of defects and clinical bone healing process.

Subjects and Method: This was a cross sectional study. A sample of 20 patients with bone defect in the tibia and femur was selected for this study. An evaluation of radiological defect closure was evaluated using a calculation system using the FDA-determined radiological evaluation method and a periodic lower function of the LEFS (Lower Extremity Functional Scale) every 2 months up to the 6th month. The statistical tests were performed using linear regression.

Results: There is a negative relationship between the radiological value and the functional scale of the lower motion device $(b=-1.26 ; p=0.001)$. There is an improvement in bone defect closure and clinical functional improvement in patients who performed a synthetic bonegraft closure action added by BMP-2 as well. The evaluation is carried out through radiological calculations that show a periodically reduced size of the defect which affects the increase in the value of the functional scale of the lower motion device.

Conclusions: There is a negative relationship between radiological values and functional scale of lower motion devices in patients with bone defect in the tibia bone or femur given synthetic bone graft and Bmp2.
\end{abstract}

Keywords: bone defects, synthetic bone grafts and BMP-2, LEFS

\section{Correspondence:}

Farid Ibrahim. Masters Program in Family Medicine, Universitas Sebelas Maret, Jl. Ir. Sutami 36 A, Surakarta 57126, Central Java.

\section{BACKGROUND}

Fractures in the lower limbs with a severe condition, especially those associated with bone defects, often fail to heal or are slow to form bone unification. Such conditions in patients trigger clinicians to perform bonegrafting procedures as part of a procedure aimed at achieving union.
Bone Graft has been widely used along with the development of Orthopaedic surgery. W.E. Gallie2 in 1913 evaluated the use of bone grafts for defects in several parts of the bone, which were later published. In the maxillofacial field, it turned out that it had already carried out research, which was first by Von Walter in 1821 using Corticocancellous Bone Graft in 
Indonesian Journal of Medicine (2018), 3(2): 77-83

https://doi.org/10.26911/theijmed.2018.03.02.03

maxillofacial reconstruction. With the increasing number of cases related to bone defects and trauma, the development of bonegrafts also developed. The principle of bone grafting is to replace a bone defect for any reason, with another bone replacement. Bone grafting is the process of implantation or transplantation of bone from one location and then transferred to another location on the human body or from donors from humans, or from different species such as cattle, and can come from synthetic / factory-made products. There are three important processes in bone formation, namely: Osteoinduction, Osteoconduction and Osteogenesis.

The purpose of Bone Graft is to give a direct form of bone or bone component or a component that resembles a bone implanted / transplanted. For this process, there are several materials that can be used, namely: from the Cancellous, cortical bone and or from a micro or macrovascular graft.

Table 1.Various types of bone graft

\begin{tabular}{lcccc}
\hline \multicolumn{1}{c}{ Bonegraft } & $\begin{array}{c}\text { Structural } \\
\text { Strength }\end{array}$ & Osteoconduction & Osteoinduction & $\begin{array}{c}\text { Osteo- } \\
\text { genesis }\end{array}$ \\
\hline Autograft & No & +++ & +++ & +++ \\
Cancellous & +++ & ++ & ++ & ++ \\
Cortical & & & & \\
Allograft & No & ++ & + & No \\
Cancellous & No & ++ & + & No \\
Frozen & & & & No \\
Freeze Dry & ++ & + & No & No \\
Cortical & + & + & Nozen & Froze \\
Freeze Dry & S & + & & \\
\hline
\end{tabular}

Source: Greenwald S, Boden SD, et al. (2001). Bone-Graft Substitutes: Facts, Fictions, and Applications. THE JBJS.ORG, 83-A(2): 2.

Another solution is with Xenograft (heterograft) 3, which is grafting from different species. Grafting from different species must go through certain standards. The standards that are determined, such as; must be from healthy animals, free of disease, through the process of purification,
The ultimate goal is to achieve the process of solid bone tissue mineralization. "As a Gold Standard" is the use of autogenous bone graft which is taken from the patient's bone. It is stated that the use of autogenous bone graft is the administration of the main and most ideal bone graft. In its development, it is known that the use of autograft also has some disadvantages, including: pain and discomfort due to injury after the procedure, and can increase the risk of infection after surgery. To overcome this, there are alternative grafting measures. The second most use is by using Allograft. Allograft is the graft base material taken from the same species that is from humans. In this action, there are advantages and there are also drawbacks too, the disadvantages include the reaction between the host and recipient and the risk of infection.The three purification process can also reduce excess levels they have. 
There are several kinds of bone graft synthetic products, including Biosynthetic material, ceramics, various polymers, calcium sulfate hemihydrate. The most commonly used is Hydroxyapatite \& tricalcium phosphate. Hydroxyapatite is known to be a graft that has good osteoconductive properties. This hydroxyapatite has been widely used and easily obtained in the country has been widely produced. The raw materials commonly used include bovine, egg shells or other natural products. It has been widely investigated that Xenograft originating from oxen is a very useful alternative because the supply is very large, it is not difficult to carry out the purification process. In a very small way, it becomes a medium for disease transmission, especially after gamma-ray sterilization. Cancellous Bovine graft is known to have advantages in providing a high content in calcium and phosphorus and is absorbed more quickly.

In its journey, efforts were made to find ideal bone grafts in which the important elements can be met, namely as osteoconduction, osteoinduction, and osteogenesis. Ulrich Meyer inBone and Cartilage Engineering ${ }^{6}$ mentioned that the bone consisted of organic and anorganic components. The organic structure was strengthened by the matrix associated with calcium and phosphate which formed the hydroxyapatite structure. The organic structure consisted of 95\% collagen and 5\% proteoglycans. Ulrich also added 5 that collagen was the most important structure (the major constituent of the extracellular matrix network). The function of collagen was to form a microenvironment that supported the core process of bone formation

Bone morphogenetic proteins (BMPs), family of osteoinductive proteins in the bone matrix, first identified by
Marshall Urist in 1965. The first clinical report on the use of BMP from humans deextracted from demineralized bone was published in the 1980s. Although the research produced promising results, its clinical application was limited by the limited supply of human BMP that could be taken from allografts. Cloning of complementary DNA which encode human BMP-2 sequences allowed the manufacture of large amounts of rhBMP-2 with biological activity which remained consistent that could be used in clinical research.

When it was implanted in the appropriate matrix, rhBMP-2 showed a process that encouraged bone formation in various bone devices, including in the case of open tibia fractures. The mechanism of the action of rhBMP-2 involved the formation of osteoinductive signals and regulation of a number of gene expression pathways involving recruitment and differrentiation of mesenchymal progenitor cells into osteoblasts. Mesenchymalcells. When rhBMP-2 was combined with allograft and implanted in the bones of both test animals and humans, the rhBMP-2 accelerated allograft incorporation, producing results which comparable to (if not superior) than autograft.

\section{RESULTS}

The study was conducted at Prof. Soeharso orthopaedic hospitals, Surakarta, Central Java, from July 1, 2013 to December 31, 2014the results of the study in 20 patients were obtained.

\section{Descriptive Analysis}

A total of 20 patients were treated, 16 (80\%) male and 4 (20\%) female. There were 2 types of fixation for the patients, namely internal fixation and external fication. Fixation was done in 9 patients (45\%) for internal fixation and 11 patients (55\%) for external fixation. 
Indonesian Journal of Medicine (2018), 3(2): 77-83

https://doi.org/10.26911/theijmed.2018.03.02.03

Defect closure surgery was performed on the main bone of the lower part of the motion device, namely the tibia bone and femur bone. The location of the operation was performed by 10 patients $(50 \%)$ in the femur bone and 10 patients (50\%) in the tibia bone.

The side of the lower motion device involved was 12 patients (60\%) in the right side of lower motion device and 8 patients (40\%) in the left side of motion device.

Table 2. Frequency Distribution

\begin{tabular}{lcc}
\hline \multicolumn{1}{c}{ Characteristics } & Total & Percentage \\
\hline Gender & 16 & 80 \\
Male & 4 & 20 \\
Female & & \\
Fixation Distribution & 9 & 45 \\
Internal Fixation & 11 & 55 \\
External Fixation & & \\
Location Distribution & 10 & 50 \\
Femur Bone & 10 & 50 \\
Tibia Bone & & \\
Side Distribution & 12 & 60 \\
Right & 8 & 40 \\
Left & & \\
\hline
\end{tabular}

Of the 20 patients, the age range was 20 to 55 years old. The highest frequency of age was between 20-25 years old and 41 45 years old by 4 patients (20\%). There was an improvement in defect fulfillment which areradiologically assessed. The radiological measurement of size and defect evaluation was by using the formula set by previous study that has been approved by the FDA (Food and Drug Administration), which was by the formula:

((length $\mathrm{x}$ width $\mathrm{x}$ height)/2) $\mathrm{x}$ the remaining percentage of contacts in percent).

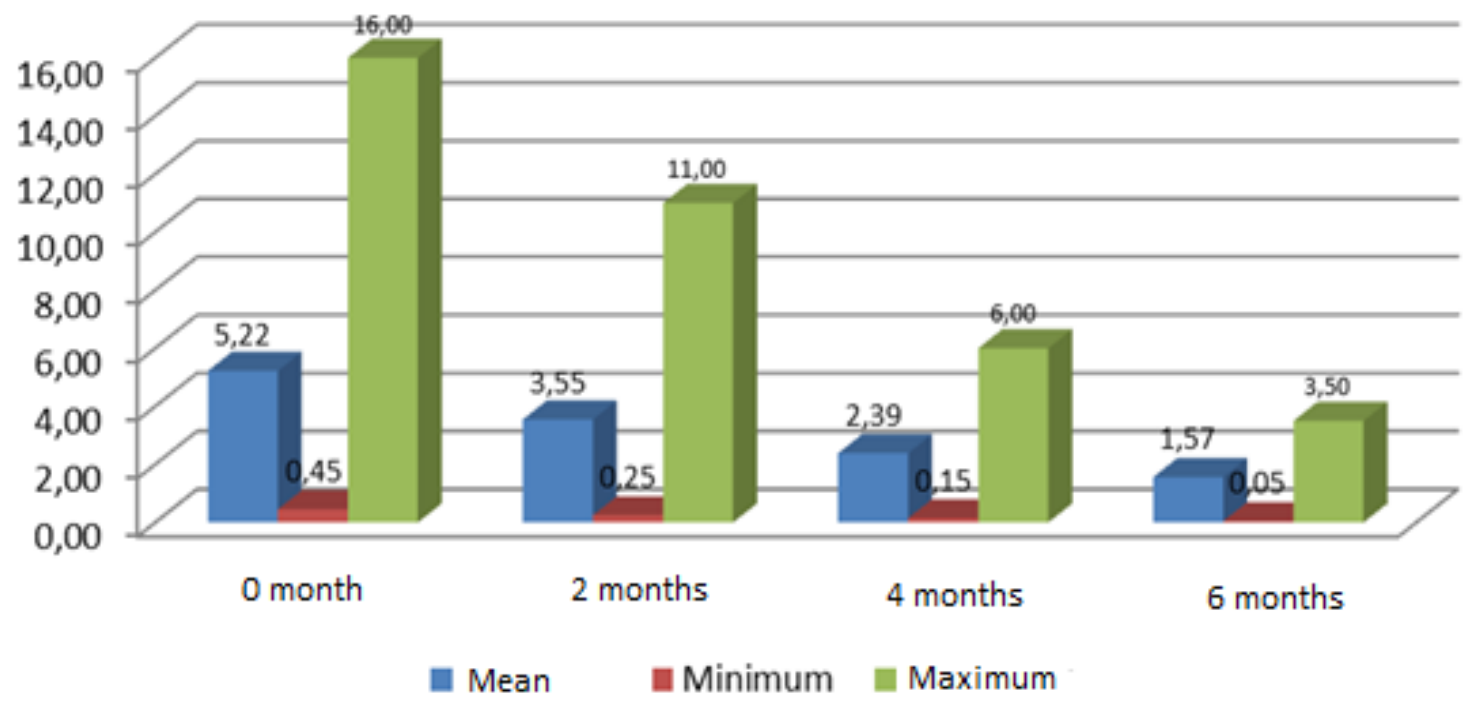

Figure 1. Graph of radiological measurements 
Ibrahim et al./ The Relationship of Radiological Value and Functional Scale

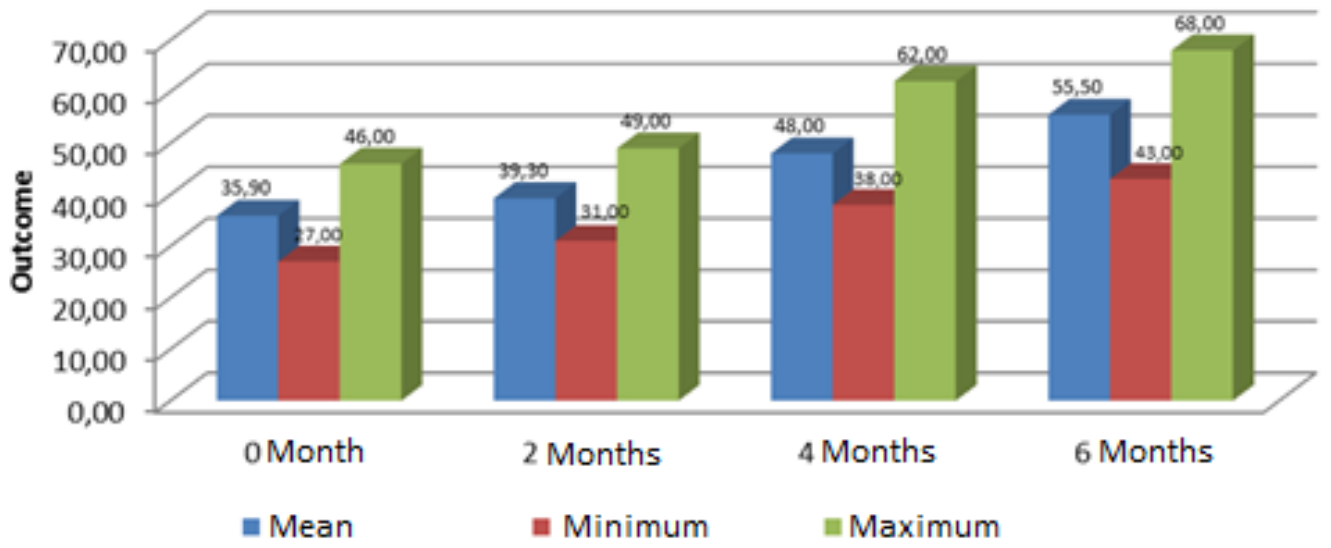

Figure 2. Graph of clinical functional scale

There was an improvement in clinical function evaluated by various LEFS (lower extremity functional scales).

It was showed that in periodic evaluation of radiological images, a decrease in

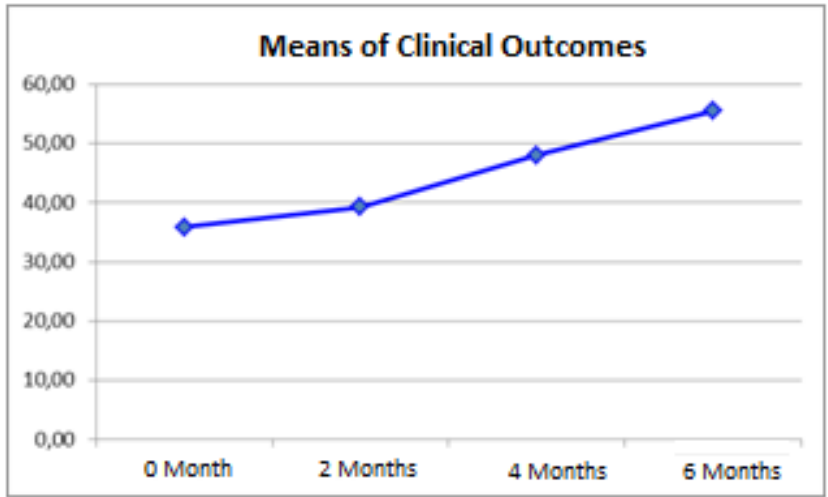

the size of the defect in the bone was inversely proportional to the functional scale of the lower motion device, as can be seen in the graph below..

Figure 3. Graph comparison of clinical and radiological conditions average
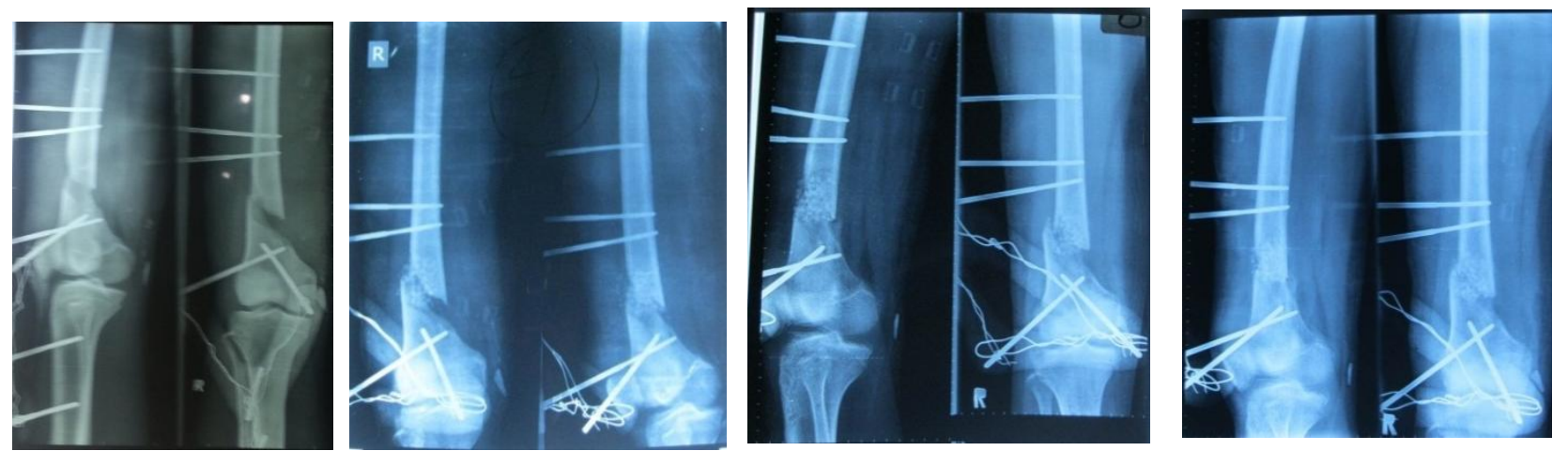

Figure 4. A 20 years old male patient photos after the o months, 2 months, 4 months, and 6 months procedures 
Indonesian Journal of Medicine (2018), 3(2): 77-83

https://doi.org/10.26911/theijmed.2018.03.02.03

\section{Bivariate Analysis}

Table 3. The results of linear regression of the relationship between radiological values and functional scales of lower motion devices

\begin{tabular}{lccc}
\hline \multicolumn{1}{c}{ Variables } & b & SE & p \\
\hline Constants & 48.70 & 1.55 & $<0.001$ \\
Radiological value & -1.26 & 0.36 & 0.001 \\
\hline
\end{tabular}

Linear regression results (Table 5) showed that there was a negative relationship between radiological values and functional scale of lower motion devices $(b=-1.26 ; p=$ 0.001).That the decrease in the size of the defect, which was evaluated radiologically had an effect of $36.8 \%$ on the increase in the functional scale of the lower motion device in patients who joined the study.

\section{DISCUSSION}

This research showed satisfactory results in the use of synthetic bone grafts accompanied by BMP-2 for patients with bone defects in the lower motion device. In the analysis conducted by William et al. (2007) stated that the use of BMP-2 and BMP-7 as osteoinductive material had a level of evidence of level 1 which supported the use in clinical importance.

A study done by Jones et al. (2006) compared the use of bone-graft and allograft/ BMP2 autologies, in cases of traumatic fractures with bone loss on bone diaphysis. The study showed the equivalent magnitude in statistical tests. The authors suggested the use of allograft / BMP-2 as a safe alternative to bone-graft autologues, and have many clinical benefits. This was consistent with the results of this study.

It can be concluded that there was a relationship between radiological values and functional scale of lower motion devices. Based on the results of the study, 20 patients (80\%) were male, and 4 patients (20\%) were female.

Periodic radiological evaluation was found to reduce the defect size in patients with bone defect in the tibia or femur who were treated with synthetic bonegraft and BMP-2 at Prof.dr. Soeharso Orthopedic Hospital.

Evaluation of clinical conditions which conducted periodically with LEFS (Lower Extremity Functional Score) was found to improve clinical value in patients with bone defect in tibia and femur who were treated with synthetic bonegraft and BMP-2 at Prof.dr. Soeharso Orthopedic Hospital.

There was a significant relationship between the reduction in the size of the defect that was evaluated radiologically with the clinical condition of the patients which evaluated by LEFS (lower extremity functional score).

\section{CONFLICT OF INTEREST}

The authors declare that there is no conflict of interest regarding the publication of this article.

\section{REFERENCES}

Brinker R, Daniel P, Connor O (2008). Basic science: Mark D. Miller Review of Orthopaedics 5th Edition: 19- 21

Canale S, Terry (2007). Campbell's operative orthopaedics, Mosby 11th ed.

Gallie WE (1913). The history of bone graft, The American Journal of Orthopedic Surgery, University of Toronto.

Greenwald S, Scott D, Boden (2001). Bonegraft substitutes: facts, fictions, and applications. The JBJS.Org, 83-A(2): 2. 
Herford AS, Dean J, (2005).Recombinant human bone morphogenic protein-2 (Rhbmp-2) use in maxillofacial surgery. Accessed from https://pdfs.semanticscholar.org/7676/ofea8bf53 c592ac6112e8ac84e1e53870aff.pdf.

Jones AL, Bucholz RW, Bosse MJ, Mirza SK, Lyon TR, Webb LX, Pollak AN et al. (2006). Recombinant human BMP-2 and allograft compared with autogenous bone graft for reconstruction of diaphyseal tibial fractures with cortical defects. A randomized, controlled trial. J Bone Joint Surg Am. 88(7):1431-41.

Meyer U, Wiesmann HP (2006). Bone and cartilage. Engineering Springer Verlag Berlin.

William G. De Long Jr., MD, Thomas A. Einhorn, MD, KennethKoval, MD, et al., (2007). Current concepts review bone grafts and bone graft substitutes in orthopaedic trauma surgery, The JBJS.Org, 89-A(3). 